\title{
Article \\ A MIMO Antenna with High Gain and Enhanced Isolation for WLAN Applications
}

\author{
Qichao Yang ${ }^{1}$, Chuanba Zhang ${ }^{1}$, Qibo Cai ${ }^{1, *}$, Tian Hong Loh $^{2}{ }^{-1}$ and Gui Liu ${ }^{1, *}$ \\ 1 College of Electrical and Electronics Engineering, Wenzhou University, Wenzhou 325035, China; \\ 194511881381@stu.wzu.edu.cn (Q.Y.); 20451840047@stu.wzu.edu.cn (C.Z.) \\ 2 National Physical Laboratory, Teddington, Middlesex TW11 OLW, UK; tian.loh@npl.co.uk \\ * Correspondence: caiqibo@wzu.edu.cn (Q.C.); gliu@wzu.edu.cn (G.L.)
}

Citation: Yang, Q.; Zhang, C.; Cai, Q.; Loh, T.H.; Liu, G. A MIMO Antenna with High Gain and Enhanced Isolation for WLAN Applications. Appl. Sci. 2022, 12, 2279. https:// doi.org/10.3390/app12052279

Academic Editor: Ernesto Limiti

Received: 21 December 2021

Accepted: 21 February 2022

Published: 22 February 2022

Publisher's Note: MDPI stays neutral with regard to jurisdictional claims in published maps and institutional affiliations.

Copyright: (C) 2022 by the authors. Licensee MDPI, Basel, Switzerland. This article is an open access article distributed under the terms and conditions of the Creative Commons Attribution (CC BY) license (https:// creativecommons.org/licenses/by/ $4.0 /)$.

\begin{abstract}
In this paper, a novel two-port dual-band multiple-input-multiple-output (MIMO) antenna with enhanced isolation and high gain is presented. The presented antenna is composed of a symmetrical ground element and two identical antenna radiating elements. At the bottom of the substrate, the ground part is applied to strengthen the isolation performance of the designed MIMO antenna. The measured $-10 \mathrm{~dB}$ bandwidth according to the input reflection coefficient $\mathrm{S}_{11}$ are $650 \mathrm{MHz}(2.25-2.9 \mathrm{GHz})$ and $980 \mathrm{MHz}(5.05-6.03 \mathrm{GHz})$, which are in strong agreement with the 2.4 $\mathrm{GHz}$ frequency band $(2.4-2.4835 \mathrm{GHz})$ and the $5 \mathrm{GHz}$ frequency band $(5.15-5.85 \mathrm{GHz})$ of wireless local area network (WLAN) applications. The measured $S_{21}$ at both the lower and the higher frequency operation bands are less than $-19.3 \mathrm{~dB}$. In the operating frequency bands, the measured gain is from $1.5 \mathrm{dBi}$ to $3.8 \mathrm{dBi}$. The measured results show that the presented MIMO antenna is a good candidate for WLAN applications.
\end{abstract}

Keywords: isolation; dual-band; MIMO antenna; WLAN

\section{Introduction}

With the widespread applications of wireless communication technologies, an everincreasing amount of data is flooded with wireless transmissions. The WLAN frequency band commonly used in wireless communications is already overcrowded. To achieve a larger channel capacity, multiple-input-multiple-output is a well-known solution [1,2]. When MIMO antennas are applied at the transmitting and receiving ends, mutual interference occurs between the antenna elements [3]. In order to work efficiently, the antenna elements must be isolated from each other [4]. Therefore, it is extremely important to reduce mutual coupling between the antenna elements in MIMO antenna design. Additionally, for the sake of portability and to keep costs down, many efforts must be made to minimize the dimension of MIMO antenna.

In MIMO antenna systems, a common approach is to isolate the two elements by increasing the distance between them. However, this will inevitably lead to a large occupied area. Within the occupied area, many methods to minimize mutual coupling have been proposed, such as the employment of band gap structures [5], decoupling networks [6,7], neutralization lines [8], defected ground structures [9] and parasitic elements [10]. These technologies reduce the coupling by minimizing, attenuating and blocking the surface currents [11].

In this paper, a compact high-gain and enhanced-isolation MIMO antenna printed on an FR4 substrate is presented for IEEE $802.11 \mathrm{a} / \mathrm{b} / \mathrm{g} / \mathrm{n} / \mathrm{p} / \mathrm{ac} / \mathrm{ax}(2.4-2.4835 \mathrm{GHz}$ and $5.15-5.85 \mathrm{GHz}$ ) applications. The radiating array consists of two miniaturized antenna elements with neutralization lines and defected structure on the ground plane. The radiating antenna element includes an inverted L-shaped short strip, a stepped strip and a rectangular microstrip feeding structure. This paper discusses and analyzes the reflection coefficients, peak gain, surface current distribution and radiation efficiency of the designed 
MIMO antenna. The dimension of the presented dual-port MIMO antenna is approximately $50 \mathrm{~mm} \times 50 \mathrm{~mm} \times 1.6 \mathrm{~mm}$.

\section{Antenna Structure and Design}

Figure 1 illustrates three steps of the presented antenna design process. Antenna 1 investigated the optimization of the position and size of the two antenna elements according to the reflection coefficients. As shown in Figure 2a, the frequency bands of antenna 1 are approximately $1 \mathrm{GHz}(2.7-3.7 \mathrm{GHz})$ and $1.7 \mathrm{GHz}(6.9-8.6 \mathrm{GHz})$. The resonance points are $3.24 \mathrm{GHz}$ and $7.6 \mathrm{GHz}$, respectively.

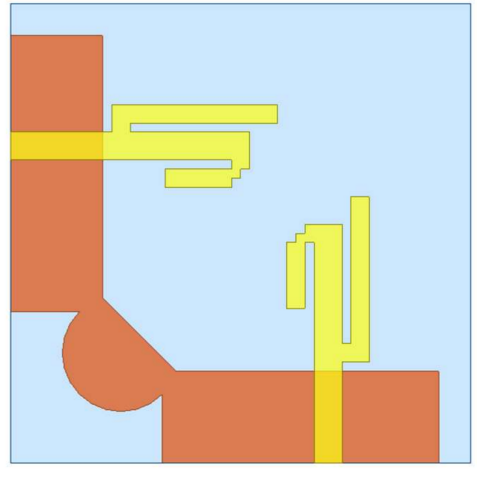

(a)

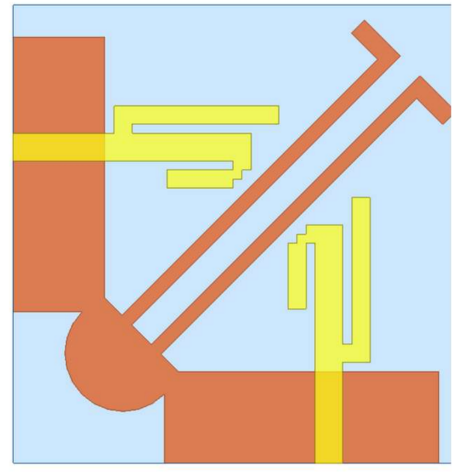

(b)

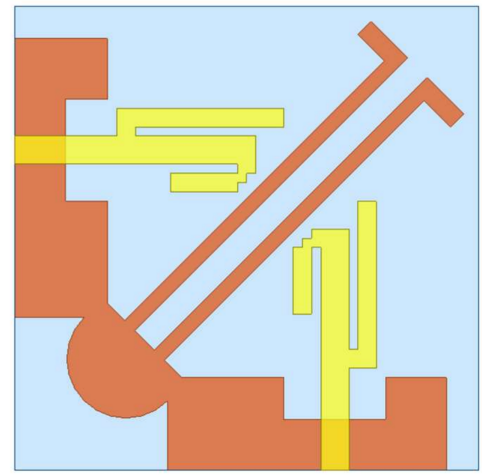

(c)

Figure 1. Structure of the designed MIMO antenna. (a) antenna 1, (b) antenna 2 and (c) antenna 3 (proposed).

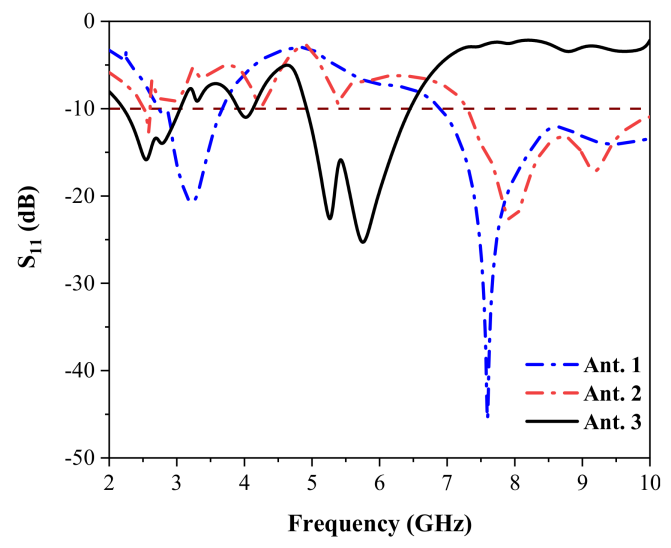

(a)

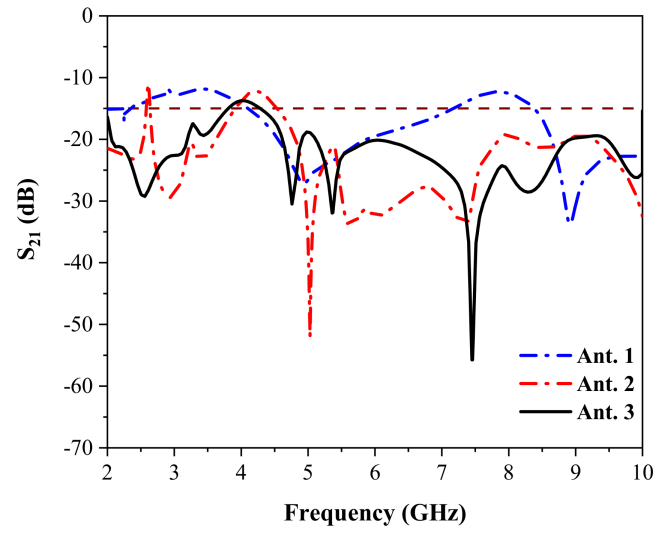

(b)

Figure 2. The simulated parameters of three antennas. (a) reflection coefficients, (b) isolation values.

Compared with antenna 1, antenna 2 has two inverted L-shaped stubs on the ground plane. As shown in Figure 2b, the $S_{21}$ parameter values of antenna 2 in the $5-7 \mathrm{GHz}$ frequency band are almost $10 \mathrm{~dB}$ smaller than those of antenna 1 . It can be seen that the L-shaped stubs greatly enhance the isolation performance at both operating frequency bands. The inverted L-shaped stubs play a role in the neutralizing line. The neutralization line structure guides the radiation field to gather along the diagonal direction of the neutralization line instead of cross-coupling effects.

Antenna 3 is the proposed antenna of this paper. A small rectangular was cut out of the ground plane to reduce the $S_{11}$ values of antenna elements in the 2-3 GHz frequency band, and the resonance point of higher frequency band was shifted to the lower frequencies. It makes the radiation field of the operating frequency band concentrated on the two elements of antenna. In Figure $2 \mathrm{a}$, the $-10 \mathrm{~dB}$ operating frequency bands of the presented antenna are 2.16-3.05 GHz and 4.92-6.45 GHz. 
The top and bottom layers of the presented antenna are shown in Figure 3. It is fabricated on an FR4 substrate with a substrate height of $1.6 \mathrm{~mm}$, loss tan $\delta$ of 0.02 and a relative permittivity $\varepsilon_{\mathrm{r}}$ of 4.4. Two radiating antenna elements are located on the top layer of the substrate. Each element includes an L-shaped short strip, a stepped folding strip and a rectangular feeding microstrip. The ground part is located on the bottom of the substrate. It is employed to improve the isolation of two elements. It is spliced together by two recessed metal elements, a semicircular strip and two opposite inverted-L-shaped strips. The two radiating antenna elements and ground plane are both symmetrical along the diagonal of the substrate.

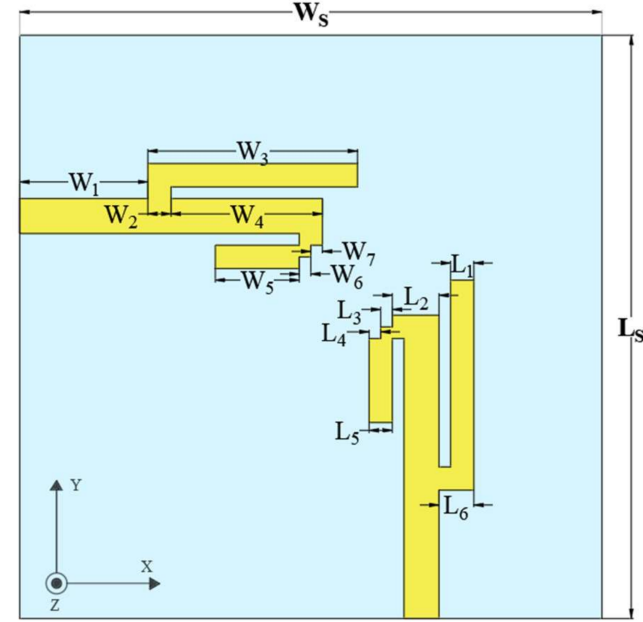

(a)

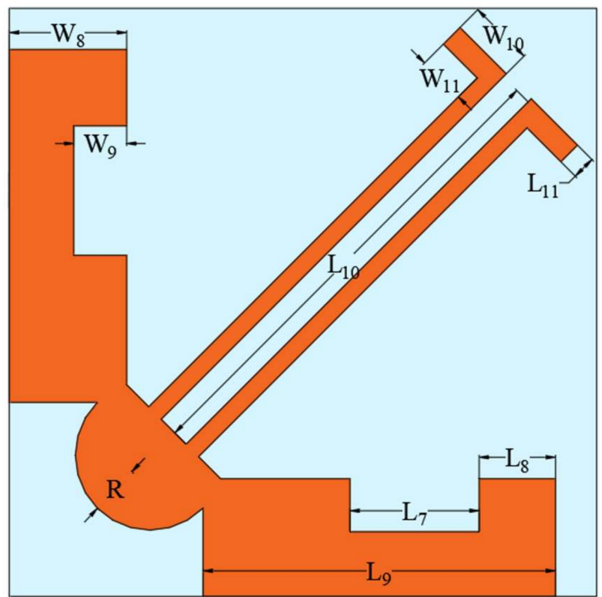

(b)

Figure 3. Structure of the designed MIMO antenna. (a) top view, (b) bottom view.

To optimize the dimension of the proposed antenna, different values of $\mathrm{L}_{1}$ and $\mathrm{W}_{9}$ have been investigated. As shown in Figure 4a, when the value of $L_{1}$ is 1.5, 2 and $2.5 \mathrm{~mm}$, the higher operating frequency band of the antenna only changes a little, but the lower frequency band changes a lot. Therefore, we can optimize the value of $L_{1}$ to tune the lower operating frequency band. As shown in Figure $4 b$, the higher frequency band changes significantly when the value of $W_{9}$ is changed. Therefore, we can optimize the value of $W_{9}$ to tune the higher operating frequency band. Therefore, the operating frequency bands are 2.16-3.05 GHz and 4.92-6.45 GHz when the values of $\mathrm{L}_{1}$ and $\mathrm{W}_{9}$ are $2 \mathrm{~mm}$ and $4.5 \mathrm{~mm}$, respectively. The final values of presented antenna dimensions are listed in Table 1.

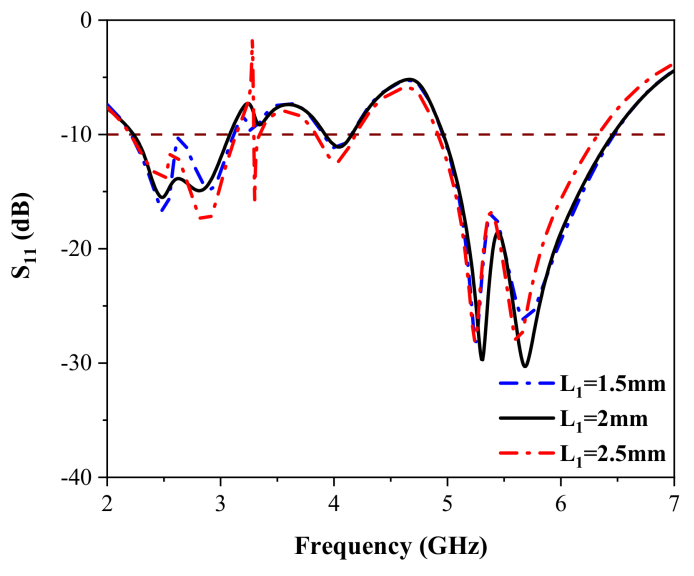

(a)

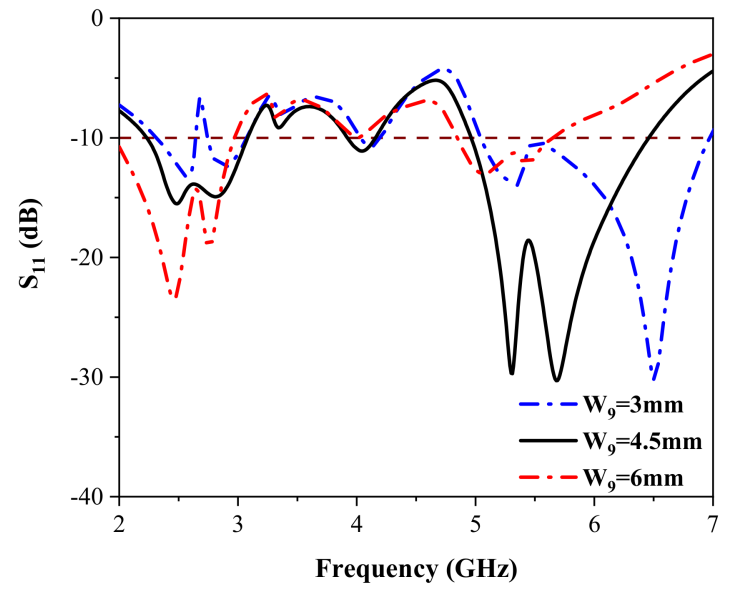

(b)

Figure 4. The simulated $S$ parameters at different values of (a) $L_{1}$ and (b) $W_{9}$. 
Table 1. Parameters of the presented antenna (unit: $\mathrm{mm}$ ).

\begin{tabular}{ccccccc}
\hline Parameter & $\mathrm{W}_{1}$ & $\mathrm{~W}_{2}$ & $\mathrm{~W}_{3}$ & $\mathrm{~W}_{4}$ & $\mathrm{~W}_{5}$ & $\mathrm{~W}_{6}$ \\
Value & 11 & 4.4 & 18 & 13 & 7.2 & 1 \\
Parameter & $\mathrm{W}_{7}$ & $\mathrm{~W}_{8}$ & $\mathrm{~W}_{9}$ & $\mathrm{~W}_{10}$ & $\mathrm{~W}_{11}$ & $\mathrm{~W}_{\mathrm{s}}$ \\
Value & 1 & 10 & 4.5 & 5.6 & 4.1 & 50 \\
Parameter & $\mathrm{L}_{1}$ & $\mathrm{~L}_{2}$ & $\mathrm{~L}_{3}$ & $\mathrm{~L}_{4}$ & $\mathrm{~L}_{5}$ & $\mathrm{~L}_{6}$ \\
Value & 2 & 4 & 1 & 1 & 2 & 3 \\
Parameter & $\mathrm{L}_{7}$ & $\mathrm{~L}_{8}$ & $\mathrm{~L}_{9}$ & $\mathrm{~L}_{10}$ & $\mathrm{~L}_{11}$ & $\mathrm{~L}_{\mathrm{s}}$ \\
Value & 11 & 6.5 & 33.5 & 41.5 & 2 & 50 \\
\hline
\end{tabular}

The designed antenna is based on linear polarization theory. The two ports adopt the same excitation mode. Figure 5 shows the current distribution of the proposed MIMO antenna when two ports are excited. At the frequency of $2.45 \mathrm{GHz}$, the main currents are focused on the stepped folding strip, the rectangular feeding microstrip and part of the inverted L-shaped strips on the ground plane. Therefore, the current intensity around the radius of $\mathrm{R}$ is small. At the frequency of $5.5 \mathrm{GHz}$, the main currents are focused on the corner of the stepped folding strips and both inverted L-shaped strips on the ground part. This confirms that, in Figure 2b, after adding L-shaped strips, the isolation of low-frequency band is significantly improved. With the defected ground structure, the current distribution in the working frequency band is mainly concentrated on the two antenna elements. The neutralization line structure promotes the cancellation of the coupled induced current between the two elements and guides the radiation field to gather along the diagonal direction of the neutralization line. In Figure $6 \mathrm{a}, \mathrm{b}$, the photographs of the top and bottom views of the fabricated antenna are presented.

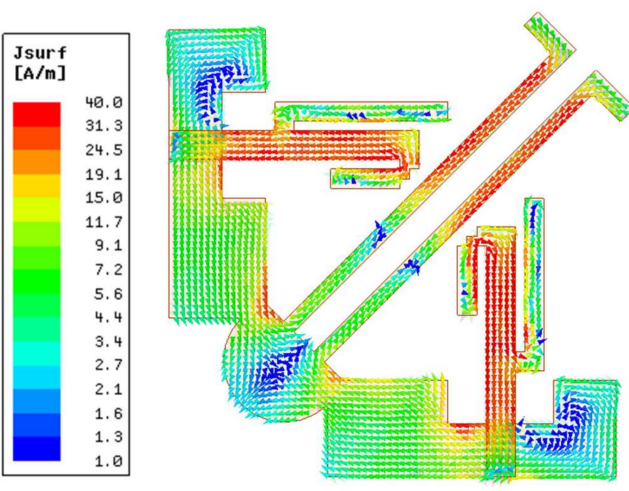

(a)

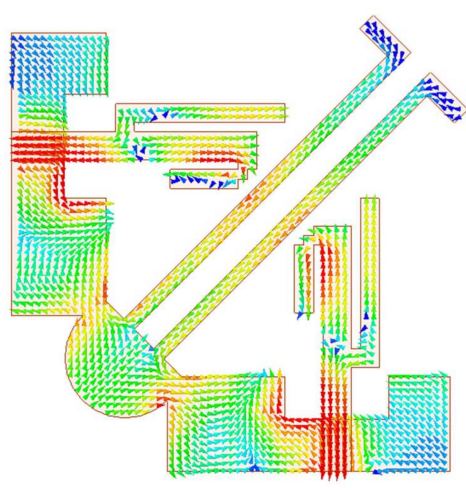

(b)

Figure 5. Simulated surface current directions. (a) $2.45 \mathrm{GHz}$, (b) $5.5 \mathrm{GHz}$.

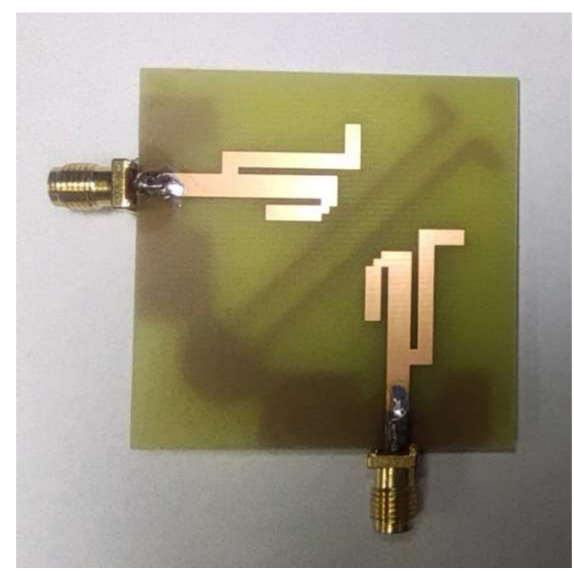

(a)

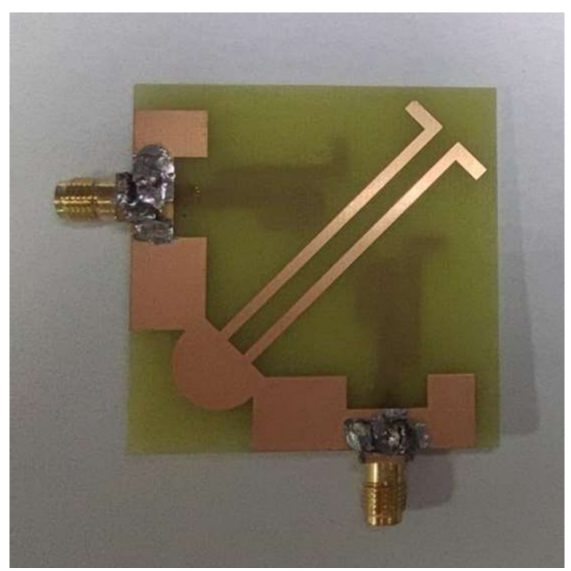

(b)

Figure 6. The photographs of the fabricated antenna. (a) top view, (b) bottom view. 


\section{Results and Discussion}

As shown in Figure $7 \mathrm{a}$, the $-10 \mathrm{~dB}$ impedance bandwidths of the measured results are $0.65 \mathrm{GHz}(2.25-2.9 \mathrm{GHz})$ and $0.975 \mathrm{GHz}(5.05-6.025 \mathrm{GHz})$, which can cover IEEE 802.11 $\mathrm{a} / \mathrm{b} / \mathrm{g} / \mathrm{n} / \mathrm{p} / \mathrm{ac} / \mathrm{ax}(2.4-2.497 \mathrm{GHz}$ and 5.15-5.85 GHz) frequency bands. Figure $7 \mathrm{~b}$ depicts the measured and simulated S21 at both frequency bands. The values of S21 are smaller than $-19.5 \mathrm{~dB}$ and $-19.3 \mathrm{~dB}$ at the lower and the higher operating frequency bands, respectively.

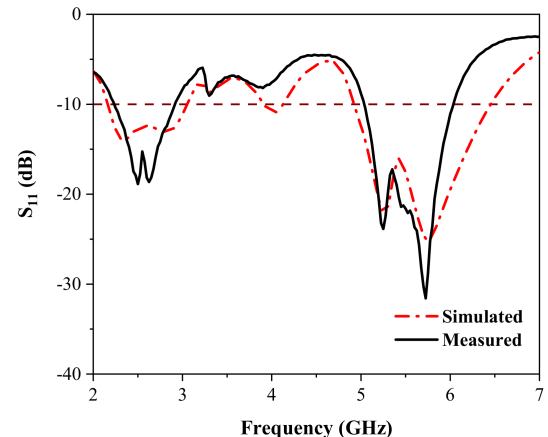

(a)

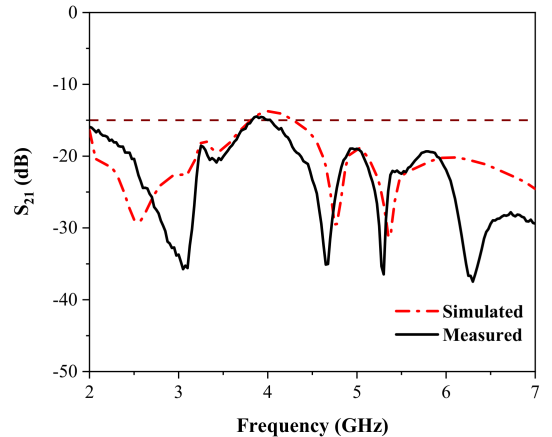

(b)

Figure 7. Simulated and measured S-parameters of presented antenna. (a) $S_{11} ;$ (b) $S_{21}$.

At the frequencies of $2.45 \mathrm{GHz}$ and $5.5 \mathrm{GHz}$, the measured radiation patterns of the fabricated antenna are illustrated in Figure 8. It can be seen from the distribution circle in Figure 8 that the superposition gain and polarization effects of the radiation field generated by the same two ports are excellent. The co-polarization is illustrated by a black solid line, the cross-polarization by a red dotted line. The antenna has a wide beam width at the desired bands, which is suitable for WLAN applications.

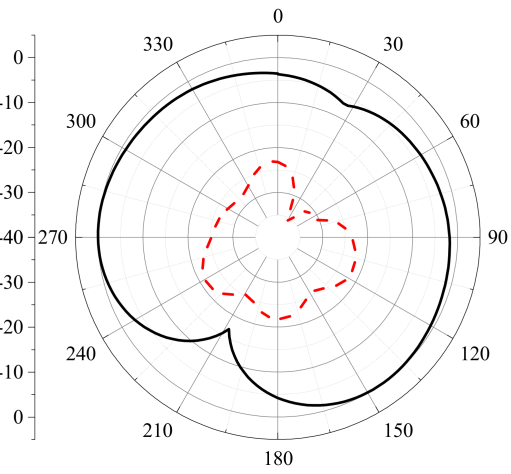

(a)

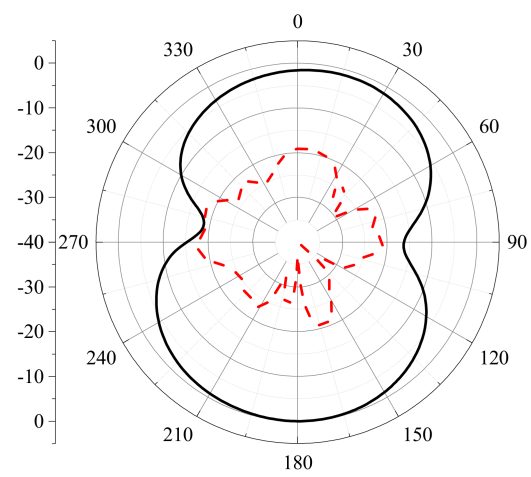

(c)

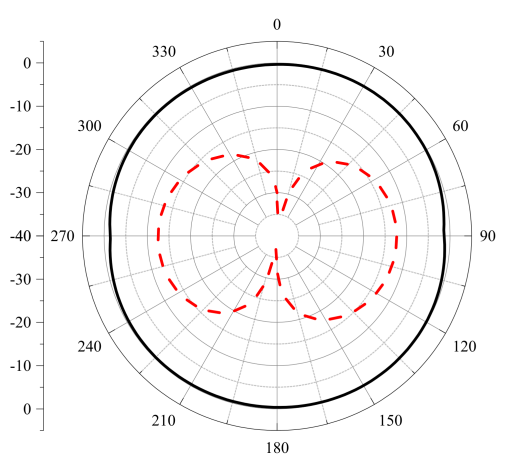

(b)

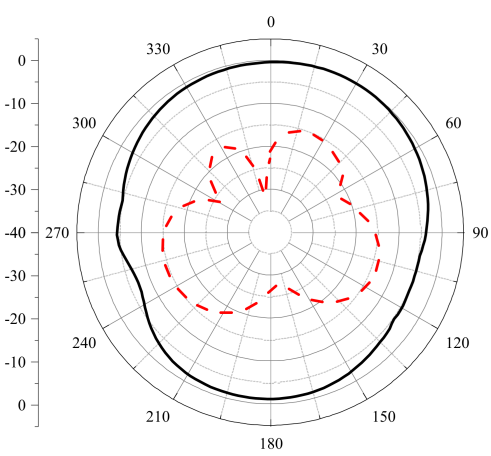

(d)

Figure 8. Radiation shapes of the fabricated antenna: (a) E-plane at $2.45 \mathrm{GHz}$, (b) H-plane at $2.45 \mathrm{GHz}$, (c) E-plane at $5.5 \mathrm{GHz}$, and (d) H-plane at 5.5 GHz. 
The envelope correlation coefficient (ECC) is an important factor used to assess the level of correlation between the communication channels [12,13]. In a MIMO system, the ECC indicates how multiple antennas are independent in the radial direction. To some extent, it can explain the correlation between radiation elements. The calculated ECC of the MIMO antenna are presented in Figure 9a. The ECC parameters of the fabricated antenna can be obtained by Equation (1):

$$
E C C=\frac{\left|S_{11}^{*} S_{12}^{\prime}+S_{21}^{*} S_{22}^{\prime}\right|^{2}}{\left(1-\left(\left|S_{11}\right|^{2}+\left|S_{21}\right|^{2}\right)\right)\left(1-\left(\left|S_{22}\right|^{2}+\left|S_{12}\right|^{2}\right)\right)}
$$

where $S^{*}{ }_{11}$ and $S^{*}{ }_{21}$ are the imaginary components of S-parameters $S_{11}$ and $S_{21}$, respectively, and $S_{12}^{\prime}$ and $S_{22}^{\prime}$ are the real components of $S$-parameters $S_{12}$ and $S_{22}$, respectively. This shows that the calculated ECC values are very low in both operating frequency bands. The maximum value of ECC at $2.45 \mathrm{GHz}$ and $5.5 \mathrm{GHz}$ is 0.026 .

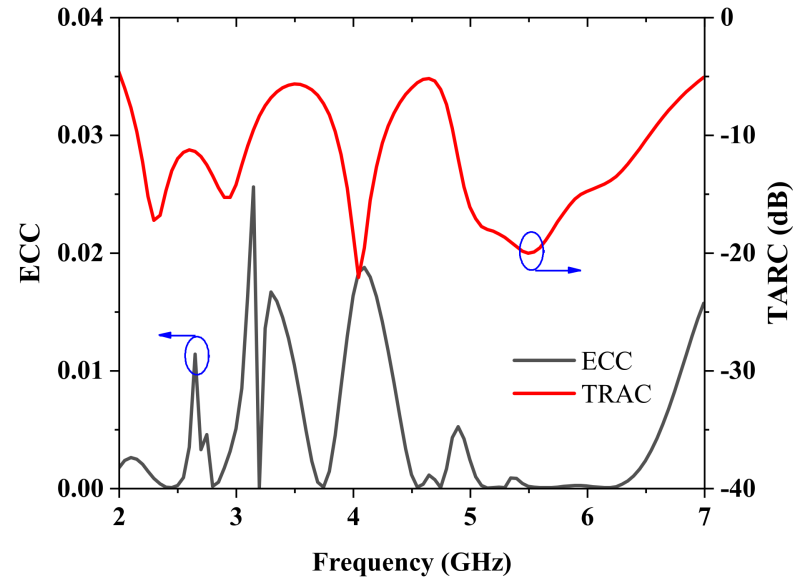

(a)

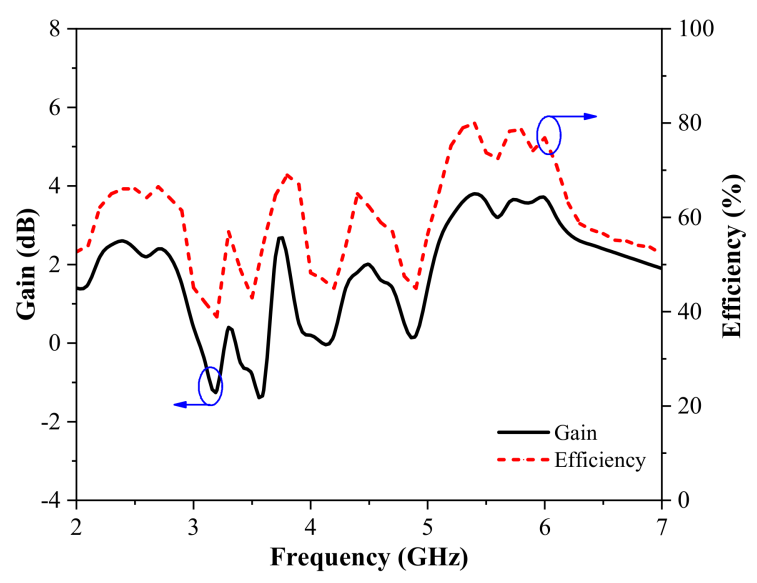

(b)

Figure 9. (a) Calculated ECC of the fabricated antenna and (b) measured peak gain and efficiency.

The total active reflection coefficient (TARC) [2] can be used to judge the impact on impedance bandwidth when adjacent antennas work at the same time. The TARC is an important index for reflecting the performance of the MIMO antenna. The TARC parameters of the fabricated antenna can be obtained by Equation (2):

$$
T A R C=\sqrt{\frac{\left(\mathrm{S}_{11}+\mathrm{S}_{12}\right)^{2}+\left(\mathrm{S}_{21}+\mathrm{S}_{22}\right)^{2}}{2}}
$$

The calculated TARC values are presented in Figure 9a. It is observed that the values of TARC in both operating frequency bands are less than $-15 \mathrm{~dB}$, which indicates that the MIMO system is stable.

The measured results of peak gain and efficiency are demonstrated in Figure $9 \mathrm{~b}$. The measured efficiencies are larger than $61.4 \%$ and $65.6 \%$ at the lower and higher operating frequency bands, respectively. The measured peak gains are $2.6 \mathrm{dBi}$ and $3.8 \mathrm{dBi}$ at the lower and higher operating frequency bands, respectively.

In Table 2, the summarized parameters include the operating frequency band, peak gain, minimum isolation and size of the designed antenna. Compared with recently published dual-band MIMO antennas, the presented antenna shows a significant improvement on peak gain. With similar occupied size, the presented antenna shows better isolation and ECCs. With similar peak gain, the presented antenna shows a smaller occupied size. The designed antenna has a better comprehensive performance. 
Table 2. Comparison with recently published papers.

\begin{tabular}{|c|c|c|c|c|c|}
\hline Reference & $\begin{array}{l}\text { Operating } \\
\text { Bands } \\
\text { (GHz) }\end{array}$ & $\begin{array}{l}\text { Isolation } \\
\text { (dB) }\end{array}$ & $\begin{array}{l}\text { Peak Gain } \\
\text { (dBi) }\end{array}$ & ECC & $\begin{array}{c}\text { Size } \\
\left(\mathrm{mm}^{3}\right)\end{array}$ \\
\hline [14] & $\begin{array}{l}2.4-2.5 \\
4.9-5.8\end{array}$ & $>14$ & 2.5 & $<0.27$ & $46 \times 20 \times 1.6$ \\
\hline [15] & $\begin{array}{c}2.25-2.41 \\
4.7-6.25\end{array}$ & $>18$ & 2.96 & $<0.2$ & $48 \times 48 \times 1.6$ \\
\hline [16] & $\begin{array}{c}2.3-2.5 \\
5-5.2\end{array}$ & $>20$ & 2.01 & $<0.05$ & $38 \times 19 \times 1.6$ \\
\hline [17] & $\begin{array}{l}2.28-2.7 \\
4.96-6.1 \\
\end{array}$ & $>15$ & 2 & $<0.06$ & $46.5 \times 46.5 \times 1.6$ \\
\hline [18] & $\begin{array}{c}2.4-2.48 \\
5.15-5.83\end{array}$ & $>15$ & 3.1 & $<0.2$ & $77.5 \times 52 \times 1.6$ \\
\hline [19] & $\begin{array}{l}2.1-2.8 \\
5.0-5.7\end{array}$ & $>20$ & 3.2 & $<0.01$ & $74 \times 47.3 \times 1.6$ \\
\hline [20] & $\begin{array}{l}2.4-2.5 \\
5.1-5.8\end{array}$ & $>15$ & 3 & $<0.1$ & $19 \times 23 \times 1.6$ \\
\hline This work & $\begin{array}{c}2.25-2.9 \\
5.05-6.025\end{array}$ & $>19.3$ & 3.8 & $<0.03$ & $50 \times 50 \times 1.6$ \\
\hline
\end{tabular}

\section{Conclusions}

A novel MIMO antenna with enhanced isolation and high gain is presented in this paper. The $-10 \mathrm{~dB}$ impedance bandwidths of the measured results are $650 \mathrm{MHz}$ (2.25-2.9 GHz) and $975 \mathrm{MHz}(5.05-6.025 \mathrm{GHz})$, which can cover $2.4 \mathrm{GHz}(2.4-2.497 \mathrm{GHz})$ and $5 \mathrm{GHz}(5.15-5.85 \mathrm{GHz})$ WLAN frequency bands. The measured isolation and peak gain at both operating frequency bands are larger than $19.3 \mathrm{~dB}$ and $3.8 \mathrm{dBi}$, respectively. The calculated ECCs are smaller than 0.026 at both operating frequency bands. The measured efficiency at the lower and higher frequency bands are greater than 0.65 and 0.61 , respectively. The experimental results exhibit that the presented antenna is preferred for WLAN applications.

Author Contributions: Conceptualization, Q.Y.; methodology, Q.C., G.L.; investigation, C.Z. writingoriginal draft preparation, Q.Y.; writing - review and editing, T.H.L., G.L.; supervision and funding acquisition, G.L. All authors have read and agreed to the published version of the manuscript.

Funding: This research work was partially funded by the Science and Technology Department of Zhejiang Province under Grant No. LGG19F010009, National Natural Science Foundation of China under Grant No. 61671330, and Wenzhou Municipal Science and Technology Program under Grant No. C20170005 and No.2018ZG019.

Institutional Review Board Statement: Not applicable.

Informed Consent Statement: Not applicable.

Data Availability Statement: The data supporting this research article are available upon request to the corresponding author.

Conflicts of Interest: The authors declare that there is no conflict of interests regarding the publication of this manuscript.

\section{References}

1. Madhav, B.T.; Usha, D.Y.; Anilkumar, T. Defected Ground Structured Compact MIMO Antenna with Low mutual Coupling for Automotive Communications. Microw. Opt. Technol. Lett. 2019, 61, 794-800. [CrossRef]

2. Usha, D.Y.; Madhav, T.B.; Anil, K.T.; Sri, K.K.; Pardhasaradhi, P. Conformal Printed MIMO Antenna with DGS for Millimetre Wave Communication Applications. Int. J. Electron. Lett. 2020, 8, 329-343. 
3. Murtala, A.; Mohamad, K.R.; Farid, Z.; Adamu, Y.I.; Kabiru, I.J.; Mohd, F.M.; Gajibo, M.; Pramudita, A.A.; Irene, K. A Compact Triband Miniaturized MIMO Antenna for WLAN Applications. AEU-Inte. J. Electron. Commun. 2021, 136, $153-767$.

4. Venkateswara, R.M.; Madhav, B.T.; Krishna, J.; Usha, D.Y.; Anilkumar, T.; Prudhvi, N.B. CSRR-Loaded T-Shaped MIMO Antenna for 5G Cellular Networks and Vehicular Communications. Int. J. RF Microw. Comput.-Aided Eng. 2019, 29, 10-1002. [CrossRef]

5. Abdalla, M.A.; Ibrahim, A.A. Design and Performance Evaluation of Metamaterial Inspired MIMO Antennas for Wireless Applications. Wirel. Pers. Commun. 2017, 95, 1001-1017. [CrossRef]

6. Huang, J.; Dong, G.; Cai, Q.; Chen, Z.; Li, L.; Liu, G. Dual-Band MIMO Antenna for 5G/WLAN Mobile Terminals. Micromachines 2021, 12, 489. [CrossRef] [PubMed]

7. Yang, R.; Xi, S.; Cai, Q.; Chen, Z.; Wang, X.; Liu, G. A Compact Planar Dual-Band Multiple-Input and Multiple-Output Antenna with High Isolation for $5 \mathrm{G}$ and $4 \mathrm{G}$ Applications. Micromachines 2021, 12, 544. [CrossRef] [PubMed]

8. Ou, Y.; Cai, X.; Qian, K. Two-Element Compact Antennas Decoupled with a Simple Neutralization Line. Prog. Electromagn. Res. Lett. 2017, 65, 63-68. [CrossRef]

9. Dou, Y.; Chen, Z.; Bai, J.; Cai, Q.; Liu, G. Two-Port CPW-Fed Dual-Band MIMO Antenna for IEEE 802.11 a/b/g Applications. Int. J. Antennas Propag. 2021, 2021, 5572887. [CrossRef]

10. Chen, Y.S.; Chang, C.P. Design of a Four-Element Multiple-Input-Multiple-Output Antenna for Compact Long-Term Evolution Small-Cell Base Stations. IET Microw. Antennas Propag. 2016, 10, 385-392. [CrossRef]

11. Nadeem, I.; Choi, D.Y. Study on Mutual Coupling Reduction Technique for MIMO Antennas. IEEE Access 2019, 7, 563-586. [CrossRef]

12. Peng, H.; Zhi, R.; Yang, Q.; Cai, J.; Wan, Y.; Liu, G. Design of a MIMO Antenna with High Gain and Enhanced Isolation for WLAN Applications. Electronics 2021, 10, 1659. [CrossRef]

13. Huang, J.; Dong, G.; Cai, J.; Li, H.; Liu, G. A Quad-Port Dual-Band MIMO Antenna Array for 5G Smartphone Applications. Electronics 2021, 10, 542. [CrossRef]

14. Soltani, S.; Lotfi, P.; Murch, R.D. A Dual-Band Multiport MIMO Slot Antenna for WLAN Applications. IEEE Antennas Wirel. Propag. Lett. 2017, 16, 529-532. [CrossRef]

15. Naidu, P.V.; Nhanekula, M.B.; Almustafa, K.M. Design and Performance Analysis of MAZE Shaped Quad Port ACS Fed Tri band MIMO Antenna for V2V and Multi Band Applications. AEU-Int. J. Electron. Commun. 2021, 134, 153676. [CrossRef]

16. Sipal, D.; Abegaonkar, M.P.; Koul, S.K. Highly Isolated Compact Planar Dual-Band Antenna with Polarization/Pattern Diversity Characteristics for MIMO Terminals. IEEE Antennas Wirel. Propag. Lett. 2019, 18, 762-766. [CrossRef]

17. Xi, S.; Huang, J.; Chen, B.; Liu, G. A Compact Dual-band Multi-input Multi-output Antenna for 5G/WLAN/Bluetooth Applications. Microw. Opt. Technol. Lett. 2021, 664, 325-3303. [CrossRef]

18. Deng, J.; Li, J.; Zhao, L.; Guo, L. A Dual-Band Inverted-F MIMO Antenna with Enhanced Isolation for WLAN Applications. IEEE Antennas Wirel. Propag. Lett. 2017, 16, 2270-2273. [CrossRef]

19. Liu, P.; Sun, D.; Wang, P.; Gao, P. Design of a Dual-Band MIMO Antenna with High Isolation for WLAN Applications. Prog. Electromagn. Res. Lett. 2018, 74, 23-30. [CrossRef]

20. Khan, M.S.; Shafique, M.F.; Naqvi, A.; Capobianco, A.; Ijaz, B.; Braaten, B.D. A Miniaturized Dual-Band MIMO Antenna for WLAN Applications. IEEE Antennas Wirel. Propag. Lett. 2015, 14, 958-961. [CrossRef] 